\title{
EKSPLORASI PENDEKATAN DESAIN UNTUK RUMAH PANGGUNG VERNAKULAR DALAM PENCIPTAAN TEMPAT KETIGA DALAM RUMAH BIRU NELAYAN MUARA ANGKE
}

\author{
Archie Trison $^{11}$, Priscilla Epifania ${ }^{21}$ \\ 1)Program Studi S1 Arsitektur, Fakultas Teknik, Universitas Tarumanagara, archietrison98@gmail.com \\ ${ }^{2)}$ Program Studi S1 Arsitektur, Fakultas Teknik, Universitas Tarumanagara, priscillae@ft.untar.ac.id
}

\begin{abstract}
Abstrak
Rumah Biru Nelayan Muara Angke adalah proyek yang berada di Kawasan Muara Angke, Kelurahan Pluit, Jakarta Utara. Proyek ini dilatarbelakangi kurangnya sarana masyarakat Muara Angke untuk beristirahat dan beraktivitas bersama. Maka dari itu, lahirlah proyek ini dengan tujuan membentuk suatu wadah tempat ketiga. Metode desain adalah metode desain vernakular dan metode perilaku keseharian. Kawasan Muara Angke sendiri memiliki genius loci yang sangat khas dibanding kawasan-kawasan lain di Jakarta sehingga pendekatan desain vernakular yang berbasis perilaku masyarakat lokal dinilai paling tepat sebagai metode dasar perancangan. Hal ini dilakukan untuk mengangkat karakter khas dari Kawasan Muara Angke yang berupa kampung nelayan. Pembentukan program berbasis perilaku masyarakat Muara Angke, salah satunya adalah menyediakan tempat istirahat bagi nelayan karena banyak nelayan yang masih beraktivitas di kapalnya karena kurangnya fasilitas yang tersedia. Kondisi pasang surut air laut yang terjadi di Kawasan Muara Angke menjadi dasar lahirnya desain menggunakan sistem rumah panggung. Rumah panggung merupakan salah satu tipologi bangunan yang identik dengan kampung nelayan karena baik dalam menghadapi kondisi jika terendam air. Rumah panggung didesain dengan beberapa aspek, yaitu menggunakan unsur material lokal bambu, penggunaan dinding anyaman bambu, atap berbentuk pelana dengan bahan bambu selubung, denah sederhana berbentuk persegi, dan massa rumah panggung dengan permainan lantai yang saling terkoneksi oleh pedestrian. Keseluruhan desain menciptakan kesan moderen, sederhana tetapi tetap mempertahankan unsur lokalitas kampung nelayan.
\end{abstract}

Kata kunci: desain vernakular; nelayan muara angke; perilaku nelayan; rumah panggung nelayan

\begin{abstract}
Muara Angke Fishermen's Blue House is a project located in Muara Angke, Pluit, North Jakarta. The project is created by the lack of facilities for the people of Muara Angke to rest and do activities together. Therefore, this project was born with a vision to form a third place. The design method used are 'vernacular design' and 'everyday behaviour'. Muara Angke itself has a very unique genius loci compared to other areas in Jakarta so that the vernacular design approach based on local people's behaviour is considered the most suitable as the basic design method. This is done to elevate characteristic of Muara Angke in the form of fishing village. The choice of program is based on the behaviour of the Muara Angke's community, one of which is to provide a resting place for fishermen because many fishermen are still do activities on their ships due to the lack of available facilities. Tidal conditions that occur in Muara Angke are the basis for the use of stilt house system. Stilt houses are one of the typologies that identic with the term of fishing village because they are good in dealing with submerged conditions. Stilt houses are designed with several aspects in the form of: using elements of local materials like bamboo, the use of woven bamboo walls, saddle-shaped roof with bamboo sheath as the material, simple square plans, then the mass of the stilt houses is designed with levelling that connected each other by pedestrian. The design creates a modern and simple impression but still retains an element of locality in the fishing village.
\end{abstract}

Keywords: everyday fishermen's behaviour; fishermen's stilt house; muara angke's fishermen; vernacular design 


\section{PENDAHULUAN}

\section{Latar Belakang}

Perkembangan dunia arsitektur pada zaman ini bergerak ke arah suatu bangunan yang bersifat individualis akibat dari era digitalisasi. Akibatnya, interaksi sosial mulai berkurang dan kebutuhan akan ruang-ruang publik semakin tinggi. Selain itu, pergerakan aktivitas yang serba cepat, yang mana aktivitas terjadi langsung dari rumah (first place) ke tempat kerja (second place) menyebabkan terjadinya peningkatan tingkat kejenuhan di masyarakat. Maka dari itu lahirlah sebuah konsep tempat ketiga (third place). Sebuah tempat untuk lari dari kejenuhan dengan tujuan untuk menciptakan interaksi sosial dan memenuhi kebutuhan masyarakatnya yaitu tempat relaksasi dan rekreasi.

Kawasan Muara Angke adalah suatu kawasan di pesisir laut Jakarta yang cocok untuk dibuat suatu proyek tempat ketiga. Kawasan Muara Angke sendiri adalah kawasan strategis yang dilewati pergerakan turis dan nelayan sebagai masyarakat lokal. Kurangnya tempat untuk beraktivitas bersama serta kurangnya tempat bagi nelayan untuk beristirahat adalah salah satu aspek mengapa kawasan ini dipilih untuk dijadikan judul proyek. Sekarang ini banyak proyekproyek baru bermunculan yang didesain abai terhadap unsur lokalitas kawasan. Hal ini dapat menyebabkan hilangnya identitas sebuah kawasan. Kawasan Muara Angke sendiri adalah kawasan yang memiliki keunikan tersendiri dibanding kawasan lain di Jakarta. Maka dari itu, untuk menghindari krisis identitas kawasan, diperlukan pendekatan desain yang berbasis vernakularitas dan perilaku masyarakat lokal.

\section{Rumusan Permasalahan}

Kurangnya sarana dan prasarana bagi masyarakat Kawasan Muara Angke membuat para nelayan sulit untuk beristirahat dan berinteraksi. Selain itu nilai lokalitas Muara Angke yang berupa kampung nelayan kian terancam akibat berbagai pembangunan di era modern ini. Studi ini berfokus pada bagaimana memberikan wadah tempat ketiga berupa tempat istirahat bagi nelayan Muara Angke yang tetap didesain tanpa menghilangkan nilai lokalitas kawasan.

\section{Tujuan}

Menjawab persoalan kebutuhan tempat ketiga di Kawasan Muara Angke dengan tetap fokus menjaga unsur lokalitas sehingga tetap mempertahankan jiwa dari Kawasan Muara Angke.

\section{KAJIAN LITERATUR}

\section{Tempat Ketiga}

Konsep arsitektur tempat ketiga (third place) adalah konsep baru yang mulai bermunculan dalam perkembangan desain arsitektur. Tempat ketiga sendiri adalah sebuah tempat komunal yang terpisah dari lingkungan rumah (first Place) dan lingkungan kerja (second Place), sebagai tempat untuk melakukan interaksi sosial dan melakukan kegiatan relaksasi (Oldenburgh, 1989). Tempat ketiga memiliki 7 poin kriteria yaitu; Level, Regular, Neutral, Accessible, Conversation, Playful, dan Unpretentious. Tempat ketiga berkaitan erat dengan kontekstualitas suatu kawasan, yang mana kekuatan lokal dari kawasan harus diangkat agar tetap bertahan dalam era perkembangan global saat ini (Sutanto, 2020). Tempat ketiga dapat juga disebut living room of society, yaitu tempat untuk melakukan kegiatan kekeluargaan/kebersamaan bagi suatu masyarakat. Dalam pembentukan tempat ketiga juga harus memperhatikan dan dapat merangsang masyarakat lokal dengan cara memasukkan aktivitas yang dibutuhkan masyarakat tersebut sehingga program yang dibentuk dapat diterima dan berlangsung dengan baik (Spaces, 2013). 


\section{Perilaku Keseharian}

Pembentuk utama genius loci suatu kawasan adalah kultur. Sebuah komunitas sosial memiliki kemampuan untuk mempelajari sebuah tradisi, bahasa, dan seni (Certeau, 1984). Gabungan dari ketiga unsur tersebut yang menentukan lahirnya suatu kultur baru. Perilaku yang dilakukan suatu komunitas pasti menggambarkan suatu kultur. Perilaku ini secara tidak langsung mempengaruhi jenis dan tata cara bagaimana suatu aktivitas dilakukan, seperti contoh: perilaku para nelayan yang memiliki kecenderungan untuk tidur di ruang yang terbuka karena sudah terbiasa tidur di kapal yang terbuka langsung ke laut, sehingga dalam pembentukan ruang arsitektur, aktivitas istirahat yang dibentuk harus disesuaikan dengan perilaku ini.

\section{Desain Vernakular}

Dalam perancangan arsitektur terdapat banyak pendekatan desain. Masing-masing pendekatan akan mempengaruhi hasil dari sebuah bangunan. Desain vernakular adalah pendekatan yang sudah lama diterapkan dalam perancangan arsitektur di seluruh dunia. Desain vernakular menekankan pada relasi bangunan terhadap konteks lingkungan, menerapkan teknologi tradisional, dan pembangunan suatu bangunan bertujuan untuk kebutuhan komunitas baik ekonomi maupun kultur (Oliver, 1997). Arsitektur vernakular dapat dideskripsikan sebagai arsitektur yang selalu merespon kebutuhan di suatu lingkungan yang dibuat oleh komunitas yang paling mengerti lingkungan tersebut. (Oliver, 2007). Desain vernakular pasti memiliki karakteristik berdasarkan partisipasi, hubungan, dan kepercayaan suatu komunitas terhadap suatu kultur atau budayanya. (Glassie, 1990).

\section{Rumah Panggung Nelayan}

Rumah panggung adalah salah satu jenis tipe rumah tropis kuno yang banyak ditemui di Indonesia, terutama di bagian bantaran sungai ataupun pesisir laut. Rumah panggung adalah jenis bangunan yang identik dengan kampung nelayan. Beberapa daerah di Jakarta yang terdapat rumah panggung nelayan adalah di Pesisir Kawasan Muara Angke, Kawasan Kampung Nelayan Kamal Muara, dan Kawasan Kampung Nelayan Muara Baru.
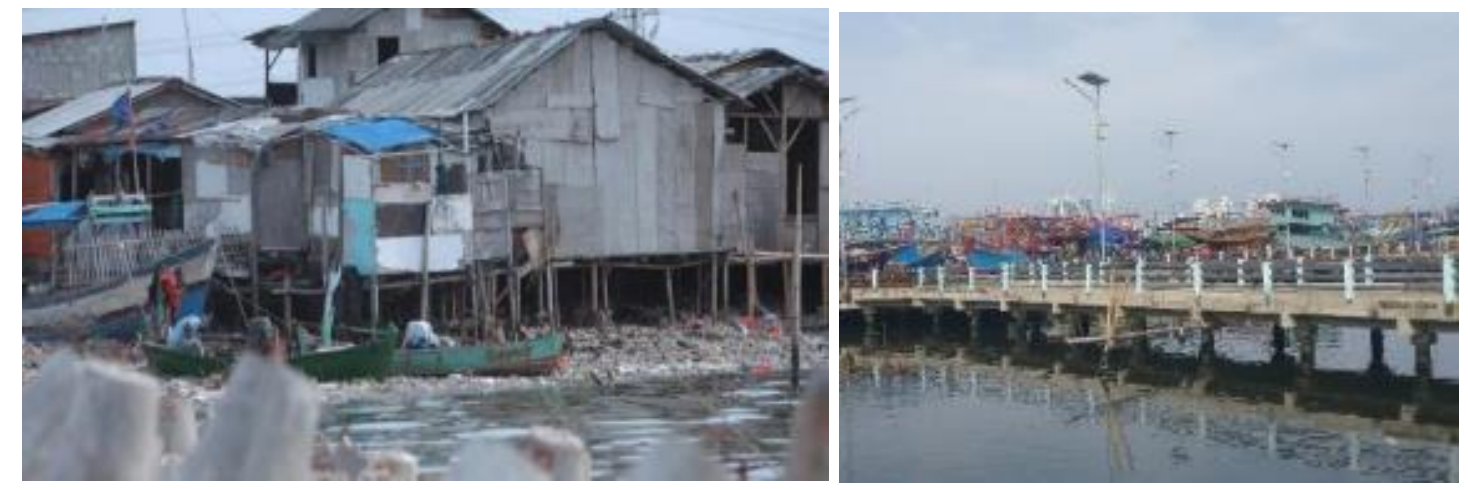

Gambar 1. Rumah Panggung Nelayan (kiri) dan Dermaga Kapal (kanan) di Muara Angke Sumber: https://megapolitan.kompas.com/read/2013/11/26/1151392/contact.html (kiri) dan Dokumentasi Pribadi, 2020 (kanan)

Rumah panggung sendiri bisa dibedakan menjadi dua yaitu rumah panggung darat dan rumah panggung nelayan. Rumah panggung nelayan memiliki ciri yang berbeda dengan rumah panggung darat. Berdasarkan tujuannya, panggung pada rumah panggung darat bertujuan untuk menghindari hewan berbahaya/predator, selain itu juga untuk tahan dari gempa. Sedangkan rumah panggung nelayan bertujuan untuk menghindari air laut/air sungai saat meluap ataupun saat pasang laut. Rumah panggung nelayan memiliki denah dengan ukuran lebih kecil, bentuk sederhana, tanpa sekat/dinding, biasa terdiri dari satu lantai, dan 
menggunakan sistem struktur yang didesain khusus agar tahan air laut dengan baik. Pada bagian kolong rumah panggung darat biasanya dapat digunakan sebagai gudang penyimpanan bahan makanan sedangkan rumah panggung nelayan selalu terendam air. Ciri yang terlihat khas pada rumah panggung nelayan adalah penggunaan kolom beton bertulang yang dibuat lebih tinggi menyesuaikan ketinggian air laut. Material yang banyak digunakan untuk rumah panggung nelayan adalah material beton, bambu dan kayu dengan jarak antar kolom dan balok minimal $1.2 \mathrm{~m}$ dan maksimal $2.5 \mathrm{~m}$.

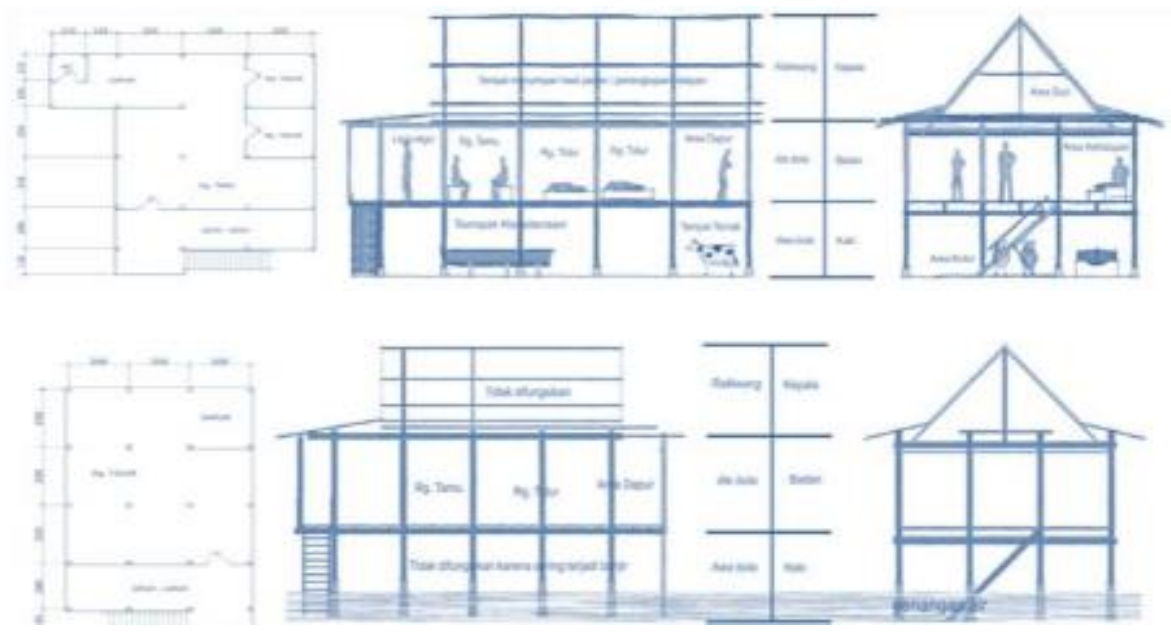

Gambar 2. Potongan Rumah Panggung Tipe Darat (atas) dan Tipe Nelayan (bawah) Sumber: (Jurmawan \& Suhartina, 2016)

\section{METODE}

Metode perancangan menggunakan dua pendekatan yaitu:

a. Metode Desain Vernakular: mencari jenis-jenis desain vernakular yang cocok untuk diterapkan di Kawasan Muara Angke. Unsur-unsur vernakular di cari dengan proses pengamatan kawasan yang dijabarkan dari iklim, figure ground, morfologi, dan material.

b. Metode Perilaku Keseharian dan Tempat Ketiga: mencari bagaimana perilaku-perilaku aktivitias masyarakat dan kriteria-kriteria tempat ketiga di Kawasan Muara Angke. Perilaku tersebut akan diteliti dan disesuaikan dengan kriteria tempat ketiga, yang nantinya akan digunakan sebagai dasar pembentukan elemen ruangan.

Kedua metode diatas dilakukan dengan pengamatan lapangan dan wawancara terhadap dua puluh lima responden. Proses observasi dan wawancara dilakukan dua hari, pada tanggal 19 dan 20 Januari 2020, pada tanggal 08.00 pagi sampai 21.00 malam. Responden yang diwawancarai mayoritas penduduk lokal Muara Angke yang berprofesi sebagai nelayan dan pedangan ikan.

\section{DISKUSI DAN HASIL}

\section{Kondisi Lokasi Studi}

Kawasan Muara Angke terletak di kecamatan Penjaringan, Kelurahan Pluit, Jakarta Utara. Pada gambar no.3 dibawah, lokasi tapak (warna merah) berdekatan dengan pelelangan ikan (A); parkiran dan pelabuhan turis Kali Adem (B); perumahan warga lokal (C); pergudangan dan pelabuhan ikan (D). Lokasi tapak berada di antara perumahan warga (first place) dan pelabuhan ikan (second place). 


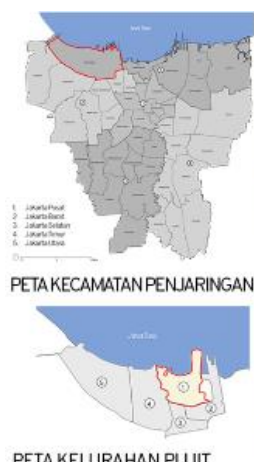

PETA KELURAHAN PLUIT
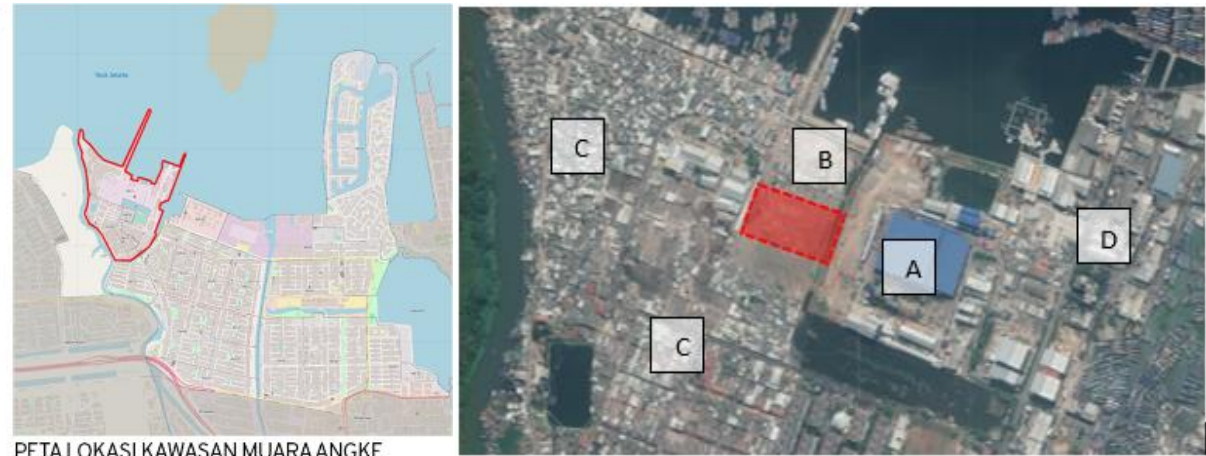

Gambar 3. Peta Lokasi Kawasan Muara Angke Terhadap Jakarta (kiri) dan Lokasi Tapak (kanan) Sumber: Olahan Pribadi, 2020

\section{Desain Vernakular}

a. Iklim: Kawasan Muara Angke yang letaknya berada di pesisir teluk Jakarta menyebabkan kawasan ini sering terendam banjir saat musim penghujan ataupun saat air pasang laut. Ketinggian level banjir beragam di berbagai titik lokasi. Bagian yang dekat dengan laut dapat terendam $50-150 \mathrm{~cm}$, dan bagian yang jauh biasa terendam $20-50 \mathrm{~cm}$ saja. Pasang surut air laut yang terjadi di Kawasan Muara Angke adalah pasang surut yang bertipe diurnal, yaitu pasang air dan air surut terjadi sekali dalam rentang waktu $24 \mathrm{jam}$. Kondisi pasang biasa mulai naik dari pukul 12.00 WIB siang dengan puncak ketinggian pada pukul 16.00WIB - 23.00 WIB lalu mulai surut saat subuh menjelang pagi.

b. Figure Ground: Kawasan Muara Angke memiliki dua tipe figure ground yang berbeda. Terdapat bentuk massa yang kecil dengan peletakan yang rapat/berdekatan dan terdapat bentuk massa yang besar dengan peletakan yang renggang/berjauhan.

c. Morfologi: Kawasan Muara Angke memiliki jenis bangunan berupa rumah panggung, rumah konvensional satu hingga dua lantai, dan bangunan pergudangangan dua hingga empat lantai.

d. Material: Material lokal yang mudah ditemukan adalah material bambu, kayu, batu-bata, dan beton. Tetapi dalam penggunaaannya, bangunan konvensional banyak yang menggunakan bata dan beton, sedangkan rumah panggung menggunakan kombinasi material bambu, kayu, dan beton.

Tabel 1. Desain Vernakular dalam Perancangan Rumah Biru Nelayan Muara Angke

\begin{tabular}{|c|l|l|}
\hline UNSUR VERNAKULAR & CIRI-CIRI DI MUARA ANGKE & KETERANGAN \\
\hline Iklim & Pasang air laut 50-150cm & Harus diantisipasi \\
\hline Figure Ground & $\begin{array}{l}\text {-Massa kecil dengan } \\
\text { peletakan yang rapat } \\
\text {-Massa besar dengan } \\
\text { peletakan berjauhan }\end{array}$ & $\begin{array}{l}\text { Dipilih satu yang terbaik } \\
\text { sebagai dasar perancangan }\end{array}$ \\
\hline close & \begin{tabular}{l} 
distance \\
\hline
\end{tabular}
\end{tabular}




\begin{tabular}{|l|l|l|}
\hline Morfologi & $\begin{array}{l}\text { - Sistem rumah panggung } \\
\text { - Rumah konvensional } \\
\text { - Bangunan pergudangan }\end{array}$ & $\begin{array}{l}\text { Dipilih satu yang terbaik } \\
\text { sebagai dasar perancangan }\end{array}$ \\
\hline Material & $\begin{array}{l}\text { - Bambu } \\
\text { - Kayu } \\
\text { - Batu-bata } \\
\text { - Beton }\end{array}$ & $\begin{array}{l}\text { Dipilih beberapa yang baik } \\
\text { sebagai dasar perancangan }\end{array}$ \\
\hline
\end{tabular}

Sumber: Olahan Pribadi, 2020

\section{Aktivitas dan Perilaku Keseharian}

Berdasarkan hasil observasi, aktivitas istirahat/tidur adalah aktivitas yang paling mencolok dan terlihat. Waktu nelayan beristirahat berada pada pukul 15.00 WIB -06.00 WIB. Istirahat nelayan di Muara Angke biasa dilakukan di kapal masing-masing. Hal ini terjadi selain karena kurangnya fasilitas peristirahatan yang layak, murah, dan terjangkau (jauh dari dermaga), juga terjadi karena perilaku para nelayan yang cenderung suka tidur di ruang yang terbuka, berhubungan langsung dengan laut, dan bersama-sama. Hal tersebut ternyata lahir dari kebiasaan para nelayan yang terbiasa pada kehidupan di tengah laut.

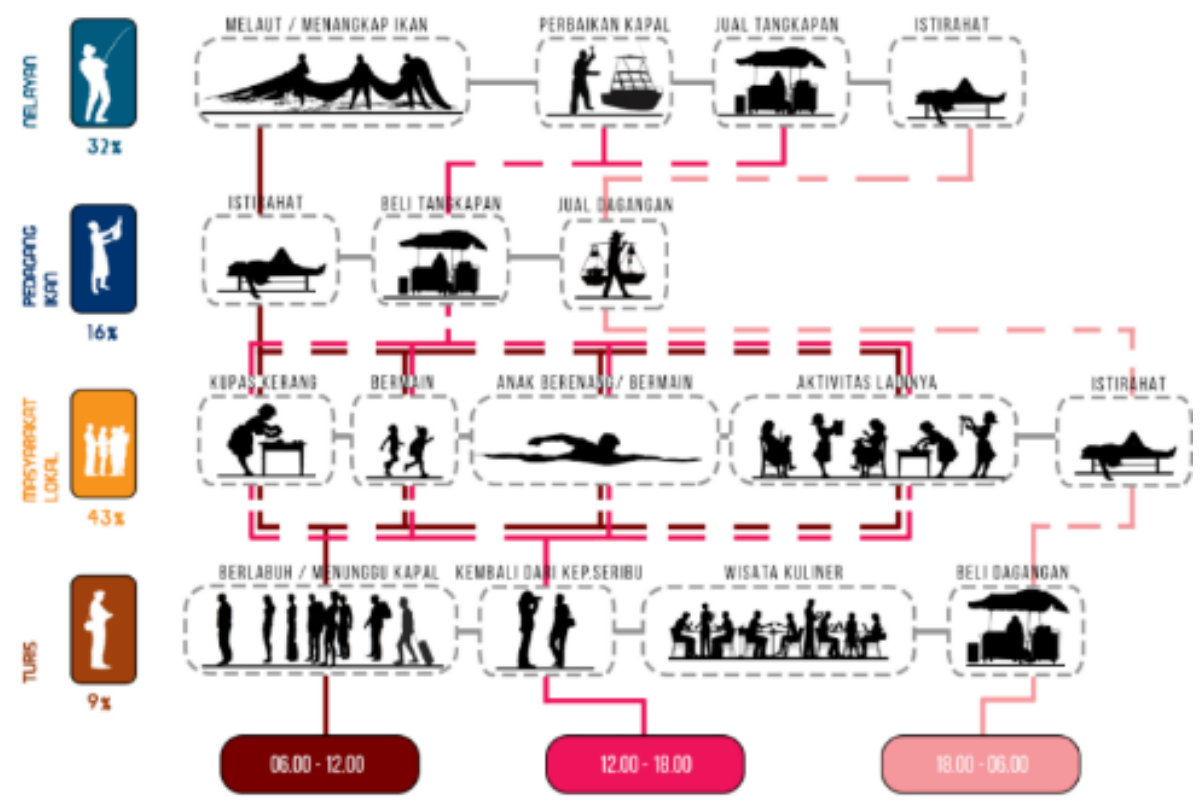

Gambar 4. Diagram Analisis Aktivitas dan Pengguna Sumber: Olahan Pribadi, 2020

\section{Desain Rumah Panggung sebagai Tempat Peristirahatan Nelayan}

Berdasarkan aspek desain vernakular dan aktivitas keseharian nelayan. Dibentuklah suatu desain yang paling cocok, yaitu pembuatan tempat peristirahatan bagi nelayan yang berbentuk rumah panggung. Rumah panggung berbentuk persegi dengan luas $4 \times 4$ meter. Dengan ketinggian di dua level yaitu -0.45 dan +3.15 , yang mana level ketinggian laut berada di -1.65 . 
Massa rumah panggung diletakkan rapat dan berdekatan, lalu dibuat berkluster dengan 4-5 massa. Rumah panggung dihubungkan dengan jalur pedestrian yang berbelok-belok, dengan lebar $130 \mathrm{~cm}$. Pada gambar no.5 di bawah, keterangan huruf ' $x$ ' adalah rumah panggung.

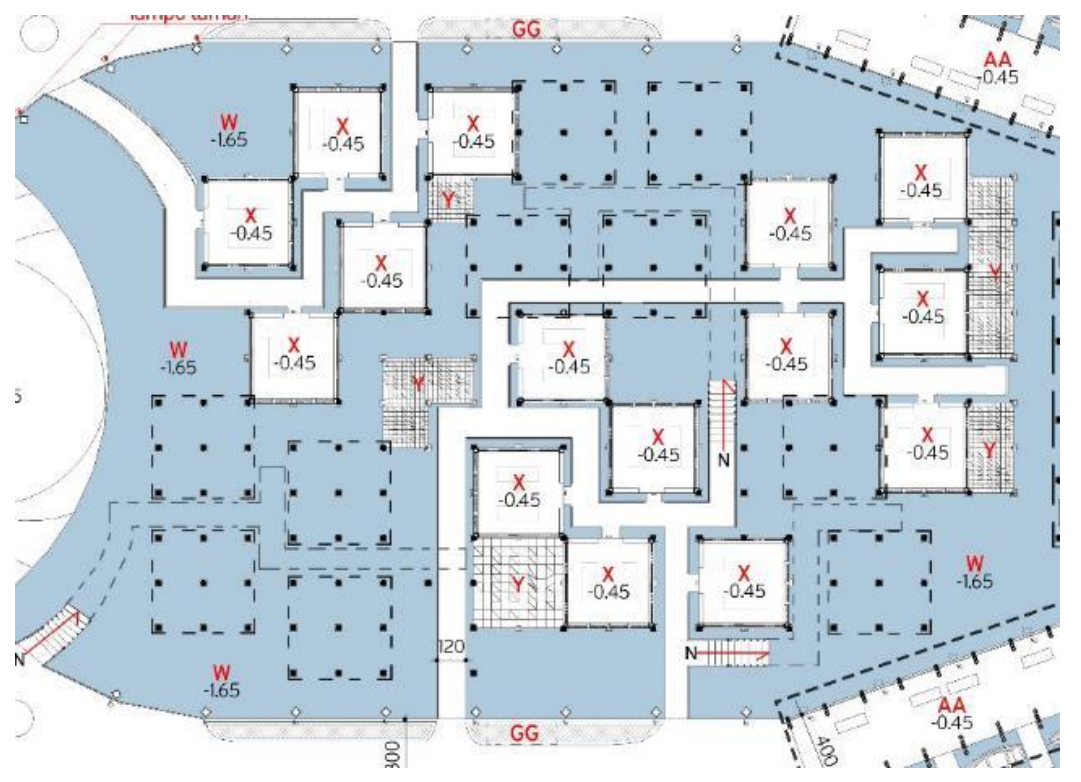

Gambar 5. Denah Rumah Panggung

Sumber: Olahan Pribadi, 2020

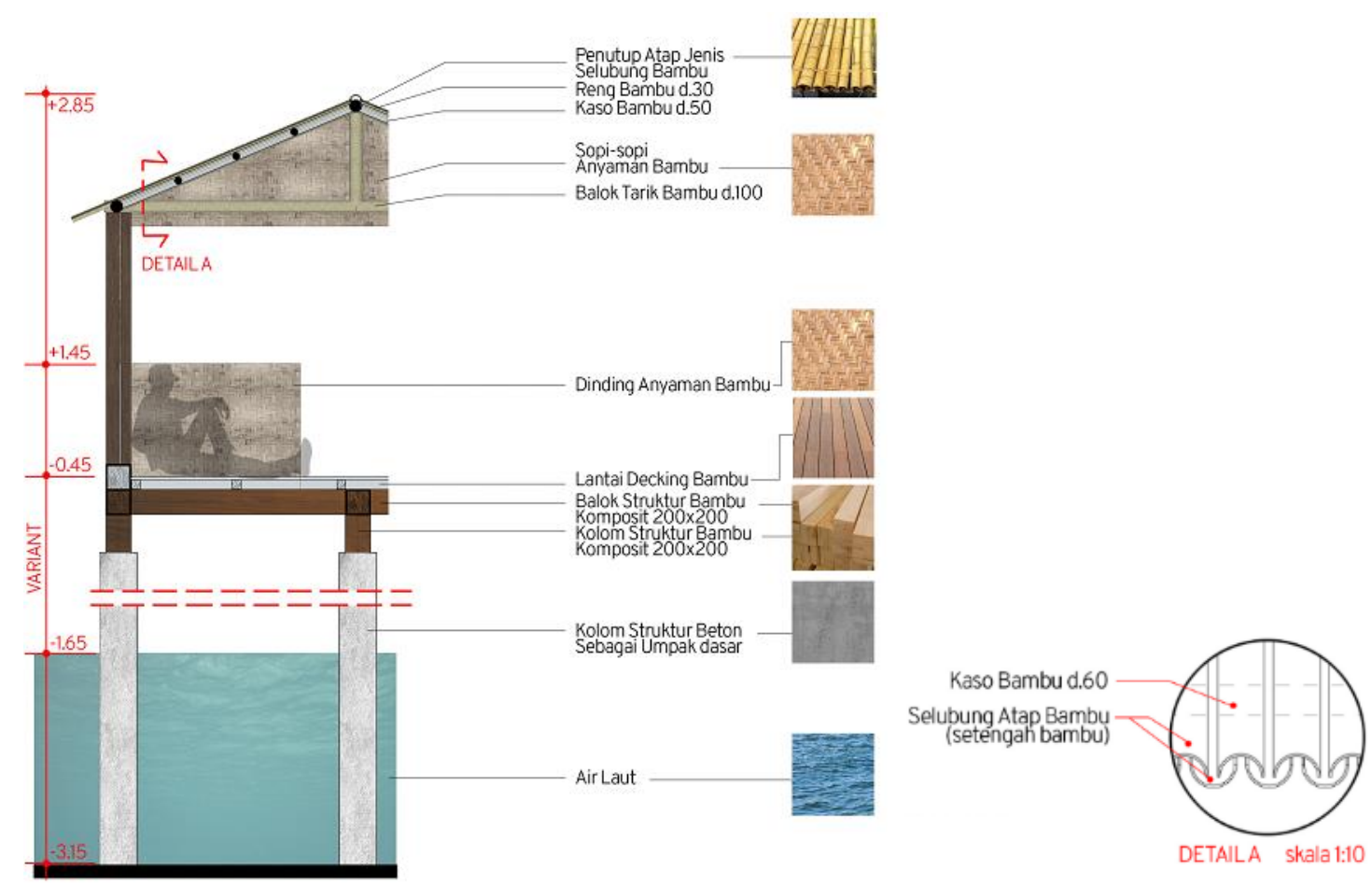

Gambar 6. Potongan Rumah Panggung

Sumber: Olahan Pribadi, 2020

Pada gambar no.6 di atas dapat dilihat bahwa, bagian kolom dan balok dari rumah panggung dibuat dengan menggunakan material bambu komposit (sudah dilapis UV agar lebih tahan lama) dan beton bertulang (kolom bagian bawah yang terendam air). Bagian dinding menggunakan bahan anyaman bambu. Dinding tidak dibuat tertutup semua, tetapi terdapat beberapa bagian yang dilubangi vertikal untuk memberikan cahaya dan pengudaraan alami. 
Bagian atap dari rumah panggung berbentuk atap pelana dengan menggunakan material bambu selubung.

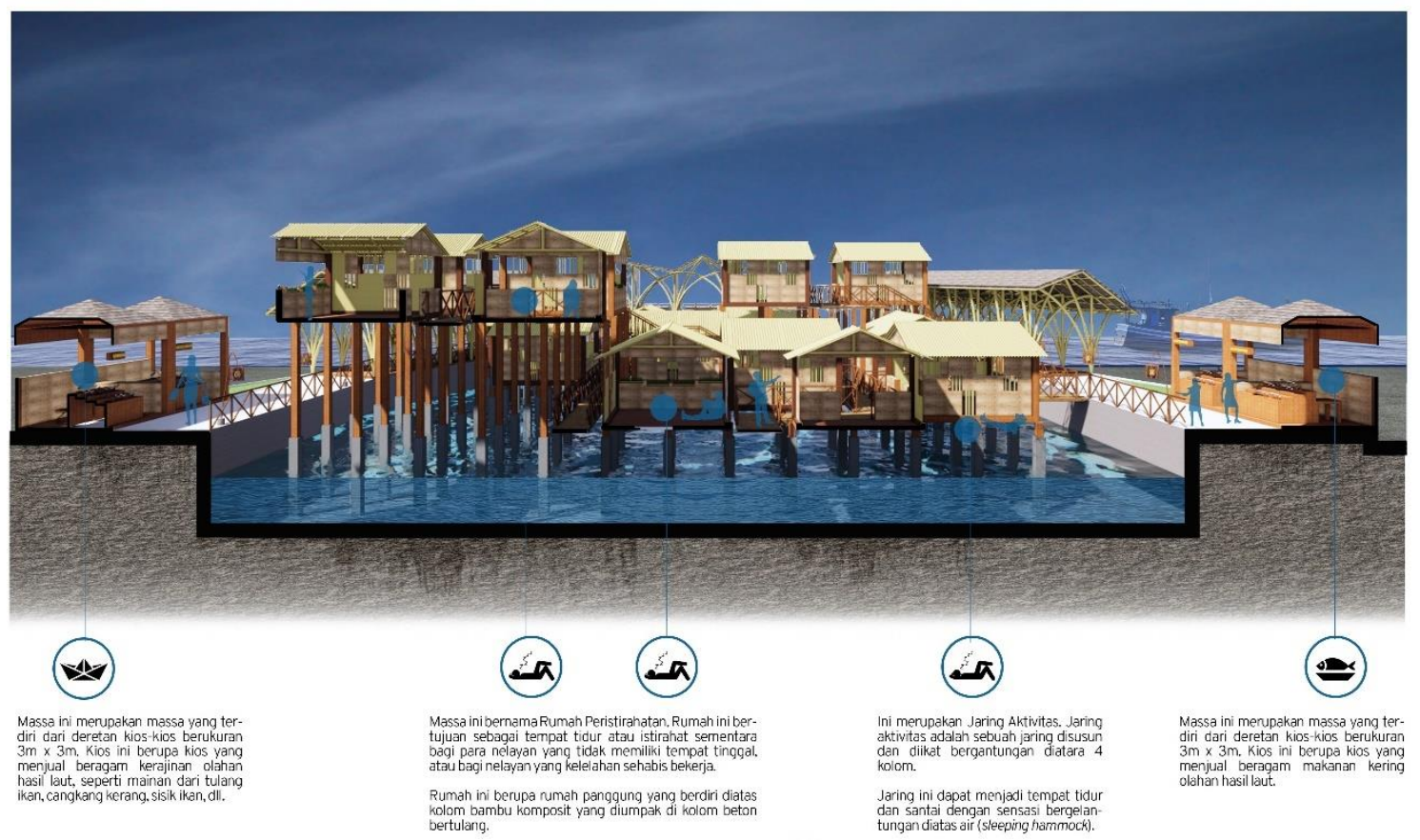

Gambar 7. Potongan Perspektif Rumah Panggung Nelayan Sumber: Olahan Pribadi, 2020

Pada gambar no.7 di atas dapat dilihat bahwa peletakan rumah panggung berdekatan dan berada pada ketinggian yang berbeda. Hal ini untuk membentuk suasana keakraban dan kebersamaan antar nelayan. Aktivitas yang dilakukan di rumah panggung bersifat terbuka, para tetangga (rumah panggung) dapat saling mendengar atau melihat, selain itu sifat terbuka ini menyesuaikan perilaku dan kebiasaan nelayan yaitu tidur di kapal. Dengan dinding dari anyaman bambu yang berlubang, nelayan yang istirahat masih dapat mendengar suara air laut, suara angin, dan suara berbincang seperti kondisi di kapal.
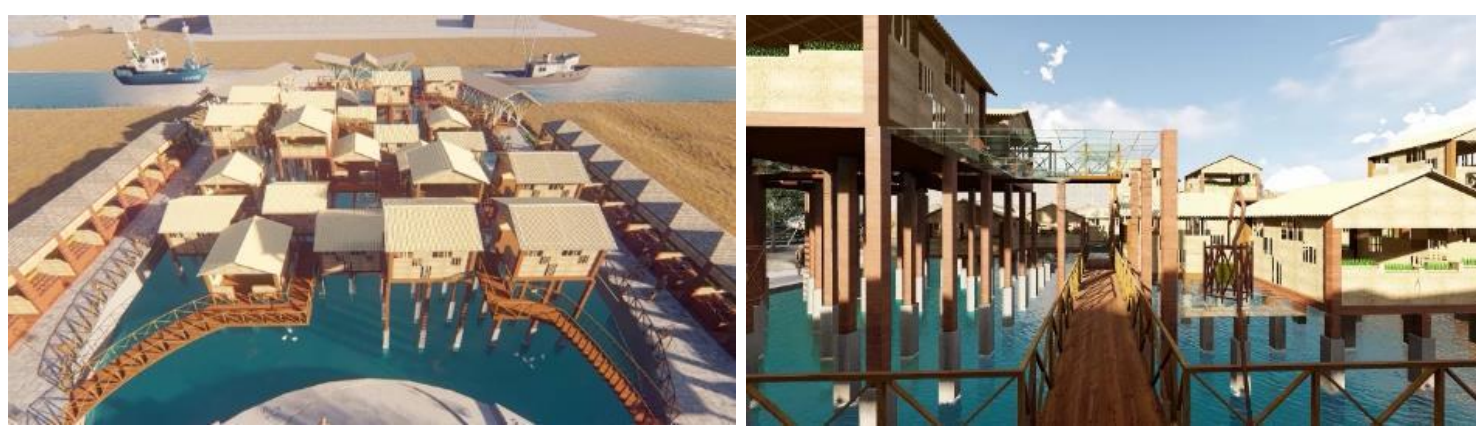

Gambar 8. Perspektif Aerial Rumah Panggung Nelayan (kiri) dan Perspektif Pedestrian (kanan) Sumber: Olahan Pribadi, 2020 

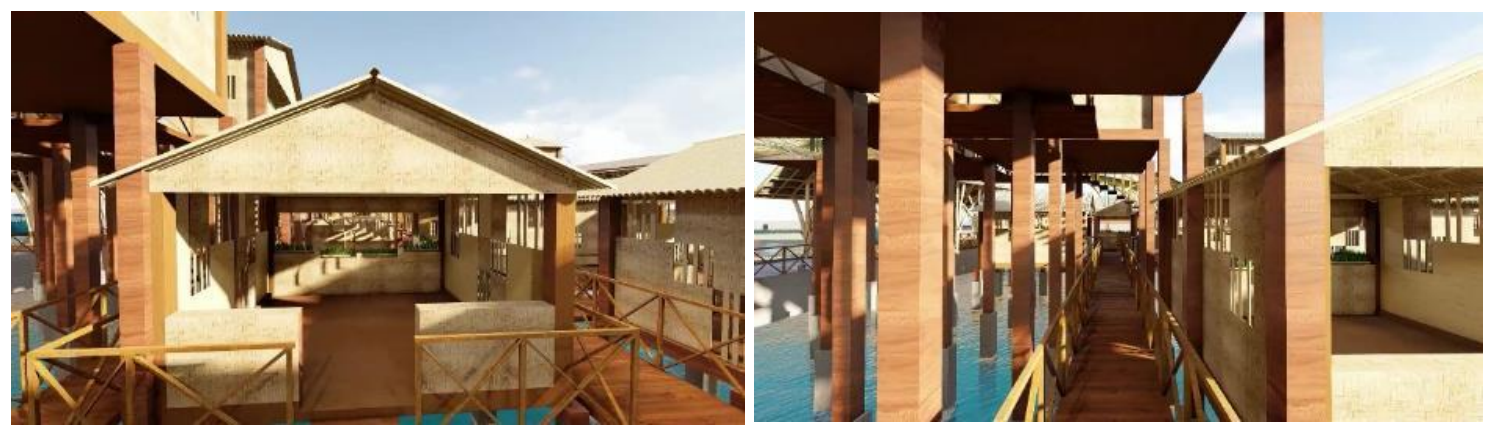

Gambar 9. Perspektif Rumah Panggung Nelayan (kiri) dan Perspektif Pedestrian (kanan) Sumber: Olahan Pribadi, 2020

\section{KESIMPULAN DAN SARAN Kesimpulan}

Kebutuhan tempat ketiga yang diperlukan di Kawasan Muara Angke adalah kebutuhan tempat peristirahatan bagi nelayan, maka dibuatlah proyek rumah peristirahatan sementara. Perancangan desain di proyek Rumah Biru Nelayan Muara Angke, menggunakan pendekatan vernakular berbasis perilaku sehingga muncullah desain rumah panggung yang digunakan untuk tempat peristirahatan nelayan. Rumah panggung didesain mengikuti aspek-aspek vernakular dan perilaku nelayan. Hal ini membuat desain sangat sesuai dengan kriteria tempat ketiga tetapi desain tidak menghilangkan genius loci dari suatu kawasan.

\section{Saran}

Dalam perancangan suatu proyek tempat ketiga, diperlukan pemahaman mendalam terhadap karakteristik khas kawasan. Aspek-aspek vernakular suatu kawasan seperti material, iklim, morfologi, dan juga aktivitas kawasan perlu dipertimbangkan. Hal ini sangat penting untuk mempertahankan kekhasan kawasan.

\section{REFERENSI}

Certeau, M. d. (1984). The Practice of Everyday Life, Volume 1. California: University of California Press.

Glassie, H. (1990). Architects, Vernacular Traditions, and Society. Traditional Dwellings and Settlements Review, Vol. 1.

Jurmawan, F., \& Suhartina. (2016). Identifikasi Rumah Nelayan Dalam Pembagian Zonasi Permukiman Di Kawasan Danau Tempe. Jurnal Ilmiah Techno Entrepreneur Acta, Vol.1 No.2.

Oldenburgh, R. (1989). The Great Good Place. New York: Paragon House.

Oliver, P. (1997). Encyclopedia of vernacular architecture of the world: Theories and principles, Volume 1. Cambridge: Cambridge University Press.

Oliver, P. (2007). Dwellings: The Vernacular House World Wide. New York: Phaidon Press.

Spaces, P. f. (2013). To Make A Great Third Place, Get Out Of The Way. Diunduh 3 Maret 2020. Project For Public Spaces: https://www.pps.org/article/to-create-a-great-third-place-getout-of-the-way.

Sutanto, A. (2020). Peta Metode Desain. Jakarta: Universitas Tarumanagara.

Taufiqurrahman, E. (2017). Seluk-Beluk Pasang Surut Air Laut. Diunduh 24 Juni 2020. Langit Selatan: https://langitselatan.com/2017/06/13/seluk-beluk-pasang-surut-air-laut/. 
